\title{
Confiança na economia colaborativa: um estudo de caso na plataforma Couchsurfing
}

\author{
Felipe Christovão Cabral Gomes ${ }^{1}$, Carla Martins Cipolla ${ }^{2}$ \\ ${ }^{1}$ UFRJ, Departmento de Engenharia de Produção, felipecgomes13@gmail.com \\ ${ }^{2}$ UFRJ, Departmento de Engenharia de Produção, Departmento, carla.cipolla@gmail.com
}

\begin{abstract}
Resumo. $O$ artigo tem como principal objetivo entender como a confiança é projetada em plataformas da economia colaborativa, identificando $e$ analisando os principais mecanismos de confiança presentes na plataforma Couchsurfing, um símbolo da economia colaborativa e líder no setor de acomodação gratuita. O método utilizado na pesquisa foi descritivo, com abordagens quantitativas $e$ qualitativas, através da elaboração de questionários e entrevistas realizadas com 106 usuários ativos da plataforma Couchsurfing. 0 objetivo foi avaliar a percepção dos usuários quanto aos mecanismos de confiança presentes na plataforma. Com base nos dados e relatos obtidos pelos questionários e entrevistas, foram identificados os mecanismos mais relevantes sob a ótica dos usuários, além de suas percepções sobre a qualidade dos serviços oferecidos pela plataforma. Em decorrência do tempo disponível, a pesquisa foi realizada apenas com usuários residentes da cidade do Rio de Janeiro, não sendo possivel afirmar que os resultados sejam válidos em outros países, principalmente com culturas que divergem muito do Brasil. Os resultados servem como um direcionamento para futuros novos empreendimentos que anseiam priorizar a segurança de seus usuários, assim como para plataformas já existentes reformularem suas estratégias e melhorarem a sua gestão da confiança. No âmbito social, os resultados dão voz aos usuários da comunidade Couchsurfing, auxiliando no entendimento de suas necessidades e identificando os pontos fortes e oportunidades de melhorias na plataforma. O estudo tem como contribuição original a análise de mecanismos de confiança sob a visão de moradores do Rio de Janeiro, uma cidade com características adversas e graves problemas de segurança pública.
\end{abstract}

Palavras-chave. Economia Colaborativa ; Confiança ; Couchsurfing ; Serviços Colaborativos 


\section{Introdução}

Não é difícil de se afirmar que estamos vivendo o auge da era da informação. Basta olhar para os lados e perceber que estamos completamente rodeados de modernas e sofisticadas tecnologias, que nos permitem entrar em contato facilmente com pessoas do outro lado do mundo, ter acesso a milhares de informações e notícias instantaneamente e fazer compras e solicitar os mais variados serviços através de um smartphone.

A grande escala de produção alcançada pelo ser humano nos últimos séculos foi responsável pelo cenário descrito acima, possibilitando avanços em praticamente todos os setores da economia, e aumentando a qualidade e expectativa de vida de uma grande parcela da população mundial.

Contudo, principalmente a partir da década de 50, vivenciamos uma transformação do padrão de consumo da população que se tornou insustentável para as próximas gerações, ameaçando o bem-estar do planeta e dos seres vivos que o habitam.

Ao longo das últimas décadas, aumentou-se consideravelmente a preocupação, tanto por parte dos governantes como por parte da população, com os impactos sociais, ambientais e econômicos decorrentes do nível de produção e consumo da sociedade. Muitos cidadãos passaram a repensar seus padrões de consumo, tornando-se mais conscientes e engajados. Isso fez com que um número maior de pessoas se tornasse mais flexível a novas formas de consumo, e que organizações buscassem inovar seus métodos e processos para atender essa crescente demanda (MOHLMANN, 2015).

A inovação social surge como uma resposta a esses problemas e necessidades da sociedade. Moulaert et al (2005) definem inovação social como toda a mudança em agências e instituições que tem como resultados a inclusão de indivíduos excluídos e grupos de minorias em diferentes esferas da sociedade. Já Howaldt et al (2013) afirmam que inovação social engloba novas práticas e processos que são adotadas e/ou desenvolvidas com o objetivo de lidar com necessidades sociais urgentes e para resolver desafios encontrados na sociedade de uma maneira melhor do que as já existentes.

De acordo com Molz e Gibson (2012), por causa dos avanços tecnológicos, popularização da Internet e surgimento de redes sociais nas últimas décadas, a inovação social pode ser vista como um processo de inovação colaborativa, onde o processo é realizado através da cooperação e coprodução de vários atores.

Esse fenômeno é capaz de gerar transformações nas práticas e relações entre indivíduos, e até entre setores da economia, como o setor de turismo por exemplo. A economia colaborativa pode ser considerada um grande facilitador de inovações sociais no setor do turismo, modificando a estrutura tradicional da organização social e dando abertura para novas interações interpessoais (MOSEDALE; VOLL, 2017).

De acordo com Leadbeater (2008), o século XX foi marcado pelo consumo desenfreado, pelo acesso ao crédito e pela definição do indivíduo pelo que possui. Já no século XXI, os cidadãos serão definidos por sua reputação, pela comunidade da qual participa e pelos bens e serviços que consegue compartilhar e ter acesso, conhecido como a era da economia colaborativa. 
Dessa forma, o presente artigo tem como principal objetivo analisar o crescente fenômeno da economia colaborativa e entender como a confiança é projetada nesses serviços, identificando os principais mecanismos de confiança existentes através de um estudo de caso na plataforma Couchsurfing.

\section{Referências Bibliográficas}

\subsection{Economia Colaborativa}

Nos últimos anos muito se tem comentado sobre a denominada economia colaborativa. Trenz et al (2018) constatam que há uma grande diversidade de termos relacionados a economia colaborativa na literatura, como consumo baseado em acesso, consumo colaborativo, estilo de vida colaborativo, economia sob demanda, economia por pares, economia de plataforma, etc. Portanto, há uma série de termos diferentes que, no geral, se referem a práticas semelhantes. Nesse artigo, será utilizado o termo "economia colaborativa".

Segundo Botsman e Rogers (2010), a economia colaborativa vem se tornando um fenômeno econômico, tecnológico e social, repensando a maneira como o consumo é realizado na sociedade e valorizando o compartilhamento em detrimento da posse. Os autores afirmam que esse fenômeno tem o potencial de ser tão marcante como a revolução industrial.

A empresa de consultoria PWC (2015) afirma que a economia colaborativa é um setor que vivenciará, ao longo dos próximos anos, um aumento exponencial de suas receitas ao redor do mundo. De acordo com suas projeções, ela partirá de um valor de 15 bilhões de dólares, registrado em 2015, e alcançará 335 bilhões de dólares em 2025.

Nos últimos anos, tem ficado cada vez mais perceptível que essa tendência está alterando o padrão de comportamento dos consumidores. Cada vez mais pessoas utilizam serviços como os de compartilhamento de carros como car2go e Zipcar, serviços de compartilhamento de casas e apartamentos, como Airbnb e Couchsurfing, serviços de compartilhamentos de livros, DVDs e jogos, como Swaptree e ReUselt, entre outros (MOHLMANN, 2015).

As novas organizações e novos serviços que estão surgindo estão influenciando comportamentos que não seriam imagináveis há poucos anos atrás, como entrar em carros de desconhecidos e receber desconhecidos em nossas casas (TANZ, 2014).

A economia colaborativa não se baseia em pedir que as pessoas compartilhem por bondade e gentileza. Trata-se de um sistema que permite que indivíduos consigam compartilhar recursos por espontânea vontade, sem ameaçar seus estilos de vida nem abrir mão de suas liberdades individuais (BOTSMAN; ROGERS, 2010).

De acordo com Mohlmann (2015), existem uma série de fatores que tornam a economia colaborativa uma opção satisfatória e influenciam fortemente aos usuários a recorrerem a esse tipo de serviço novamente, sendo eles o pertencimento a uma comunidade, a redução de custos, o impacto ambiental, a familiaridade com o serviço, funcionamento online, afinidade a tendências, utilidade e por fim, a confiança.

A confiança é o fator chave para o funcionamento de serviços colaborativos, tanto a confiança na plataforma que provê o serviço quanto nos demais usuários que 
são membros da plataforma. Um serviço que consegue projetar e gerenciar a confiança de um usuário, através de uma série de mecanismos, é capaz de atrair e reter um grande número de usuários.

\subsection{Confiança}

Uma das definições de confiança mais utilizadas na literatura é a de Mayer et al (1995), que afirmam que a confiança pode ser definida como a "disposição de uma parte em ser vulnerável às ações de outra parte, na expectativa de que o outro irá cumprir uma ação importante, independente da sua capacidade de controlar essa outra parte".

Nos últimos séculos, a confiança era algo perceptível apenas entre membros da família e amigos próximos, por haverem fortes laços entre os indivíduos, formando uma comunidade íntima, com normas e comportamentos comuns estabelecidos. Contudo, a participação de usuários na economia colaborativa, por meio de plataformas, permitiu que usuários se conectem com uma gama de indivíduos de uma maneira nunca antes presenciada na história da humanidade. Mas apesar da grande quantidade de interações que podem ser feitas, estas interações são caracterizadas, em sua maioria, por um viés de incerteza e desconfiança.

O modo no qual se analisa e constrói a confiança na economia colaborativa é muito mais complexa do que comparada com setores da economia tradicional. Um dos motivos é que a economia colaborativa se diferencia da tradicional em diversos aspectos.

Um dos aspectos é o número de participantes do serviço. Enquanto na economia tradicional há dois principais atores, o usuário e o provedor do serviço, na economia colaborativa há três atores, o usuário do serviço, um intermediário e demais usuários que compartilham do serviço (MÖHLMANN, 2016). Desta maneira, o estudo da confiança em serviços colaborativos deve levar em consideração dois aspectos, a confiança entre o usuário e o intermediário provedor da plataforma, e a confiança entre os usuários que compartilham os serviços na plataforma.

Ainda de acordo com Möhlmann (2016), a confiança na economia colaborativa é transferida de uma parte para a outra de forma hierárquica, conhecida popularmente como efeito transbordamento (spill-over effect). A confiança estabelecida no intermediário, que provê a plataforma, conquistada através de uma marca consolidada e reconhecida, acaba influenciando a confiança nos pares no qual se compartilham os serviços na plataforma.

Outro aspecto é a transferência de posse. Na economia colaborativa, os usuários podem ceder ou ter acesso a recursos apenas de forma temporária, ou seja, o recurso deve ser devolvido no mesmo estado em um espaço de tempo pré-definido (ERTZ et al, 2016). Além disso, na economia colaborativa não há recorrência das interações, ou seja, na maioria das vezes não se repetem. Dessa maneira, serviços colaborativos não permitem a simples transferência de conhecimento que um indivíduo possui adquirida de uma experiência passada, como na economia tradicional (FANG et al, 2014).

Dessa maneira, é possível afirmar que um dos principais desafios da economia colaborativa é conseguir mitigar a incerteza, desconfiança e aversão ao risco inerentes do ser-humano através do projeto e investimento em mecanismos de confiança entre 
estranhos que interagem entre si através de uma plataforma (MÖHLMANN; GEISSINGER, 2018).

\section{Metodologia}

O método utilizado nesse artigo foi descritivo, com a combinação de uma pesquisa quantitativa e qualitativa sobre a percepção de usuários ativos da plataforma Couchsurfing sobre a segurança na plataforma e os mecanismos de confiança utilizados pela mesma.

A abordagem quantitativa da pesquisa consistiu na elaboração de um questionário online com perguntas envolvendo a opinião dos usuários quanto a relevância de determinados mecanismos de confiança e a percepção dos usuários quanto a qualidade de determinadas funcionalidades da plataforma.

O questionário conta com 17 perguntas e teve como público-alvo usuários da plataforma Couchsurfing que moram na cidade do Rio de Janeiro. O contato com os usuários foi realizado pela própria plataforma, na qual foram enviados os questionários por meio do chat interno do site. Foram obtidas as respostas de 106 usuários.

Já a abordagem qualitativa consistiu na elaboração de uma entrevista contendo 13 perguntas mais aprofundadas, que envolviam o detalhamento da experiência do usuário com a plataforma. As entrevistas foram conduzidas através de dois meios, presencial e online, através de um formulário a ser preenchido. No total, foram entrevistados 18 usuários.

\section{Resultados}

\subsection{A Plataforma Couchsurfing e seus mecanismos de confiança}

A plataforma Couchsurfing é uma comunidade global, criada em 2014 pelo estudante Casey Fenton, e hoje é formada por mais de 14 milhões de usuários, espalhados ao longo de 200.000 cidades. Trata-se da plataforma de acomodação nãocomercial mais popular da Internet. Através do site ou aplicativo, usuários conseguem entrar em contato com outros usuários, presentes em milhares de cidades ao redor do mundo, em troca de acomodação gratuita (DECROP et al., 2018).

A indústria de acomodação vem sofrendo grandes mudanças ao longo dos últimos anos, sobretudo em decorrência da Internet e do avanço da economia colaborativa. Dessa maneira, grandes players entraram no mercado, como o Airbnb e o Couchsurfing, fazendo com que fosse possível se hospedar em uma cidade sem a necessidade de ficar em hotéis, desafiando assim o antigo monopólio de redes hoteleiras (GUTTENTAG, 2015).

O sucesso da plataforma coincide com a tendência atual de um número cada vez maior de turistas buscarem experiências mais autênticas e individuais, diferenciando-se do turismo de massa e superficial (STEYLAERTS; DUBHGHAILL, 2012). Dessa maneira, experiências que permitem um contato mais íntimo e prolongado com a população local, ou seja, que proporcionem uma imersão em seus hábitos e culturas, apresentam um grande potencial de serem transformativas (BROWN, 2009). 
Após uma revisão da literatura existente sobre confiança em plataformas colaborativas, além da análise das informações do site oficial do Couchsurfing, foram identificados sete grandes mecanismos de prospecção de confiança na plataforma, explicitados abaixo.

O primeiro mecanismo é a verificação do usuário. Apesar da plataforma Couchsurfing ser gratuita, existem algumas funções pagas, como a função de verificação do usuário. Após a aprovação do pagamento, o usuário também poderá provar sua identidade por meio da verificação de um número de celular, documento pessoal (identidade nacional ou passaporte) e endereço residencial válidos.

O segundo mecanismo é a informação declarada. Ao se cadastrar na plataforma, o novo usuário precisa preencher informações básicas de seu perfil, como o seu nome, idade, fotos pessoais, cidade onde mora, ocupação, formação, fluência em idiomas e países que já visitou. Em seguida, a própria plataforma disponibiliza campos de perguntas pessoais de cunho pessoal, afim de estimular que os novos usuários se sintam à vontade para se abrir com a comunidade.

O terceiro mecanismo são as referências. Após o fim da estadia, quando o viajante já deixou a casa do anfitrião, ambos os usuários podem avaliar como foi a experiência vivida. As referências costumam ser o mecanismo de confiança mais relevante na opinião dos usuários. As referências são o histórico de um usuário, ou seja, a maneira como ele se comportou nas últimas experiências. Portanto, elas servem como uma forma de fiscalização e controle realizada pela própria comunidade, que premia uma boa experiência vivenciada com uma referência positiva, e pune uma má experiência vivenciada com uma referência negativa.

O quarto mecanismo são as redes de amigos. A plataforma Couchsurfing possui uma função de adicionar amigos ao seu perfil. Dessa maneira, usuários podem adicionar usuários que já compartilharam uma experiência de acomodação assim como adicionar usuários que possuem interesses em comum ou que conheceram através da plataforma.

O quinto mecanismo são as redes sociais. O Couchsurfing permite que o usuário vincule a rede social Facebook em seu perfil. Essa funcionalidade é interessante pois geralmente o Facebook é uma rede social onde o indivíduo compartilha informações de seu interesse, como opiniões, interesses musicais, grupos nos quais participa e eventos de interesse.

O sexto mecanismo é a comunicação através da plataforma. É disponibilizado um chat interno, disponível através do site e do aplicativo. Segundo o Couchsurfing, comunicar-se exclusivamente pelo chat interno ajuda a equipe de suporte a ter uma rápida identificação e resolução do problema, caso o suporte seja contatado.

O sétimo mecanismo é a equipe de suporte, disponível 24 horas por dia. 0 contato com a equipe de suporte ocorre por e-mail, acionado através do preenchimento de um formulário no site da plataforma.

Esses sete mecanismos atuam de forma complementar e integrada, ou seja, para que a confiança seja maximizada, um usuário é aconselhado a utilizá-los em todas as etapas da interação com um membro da comunidade. 


\subsection{Dados obtidos através dos questionários}

Na primeira fase do questionário, foi identificada as características dos 106 usuários participantes, representados no Quadro 1 abaixo.

Quadro 1 - Dados dos Entrevistados

\begin{tabular}{ll}
\hline Dados dos Entrevistados & \multicolumn{1}{c}{ Respostas Obtidas } \\
\hline Gênero & 68 homens $(64,2 \%)$ \\
& 38 mulheres $(35,8 \%)$ \\
Faixa etária & Até 25 anos $(25,5 \%)$ \\
& Entre 25 a $34(30,2 \%)$ \\
Estado Civil & Entre 35 e $45(36,8 \%)$ \\
& Acima de $45(7,5 \%)$ \\
& Solteiro $(80,2 \%)$ \\
Cxperiência na plataforma & Casado $(13,2 \%)$ \\
& Divorciado $(5,7 \%)$ \\
& Já hospedou (83\%) \\
& Já se hospedou (72,6\%) \\
& Já realizou ambas as experiências \\
& (57,5\%) \\
\hline
\end{tabular}

Fonte: autores

A segunda fase do questionário foi analisar a percepção dos usuários quanto a importância dada aos mecanismos de confiança presentes na plataforma. Foram elaboradas afirmações e as respostas, representadas no Quadro 2 abaixo, poderiam variar em um espectro que iniciava em "Concordo totalmente" e terminava em "Discordo totalmente".

Quadro 2 - Percepção dos entrevistados quanto aos mecanismos de confiança

\begin{tabular}{|c|c|c|c|}
\hline Mecanismos de Confiança & Concordo & Neutro & Discordo \\
\hline $\begin{array}{l}\text { Avaliações / Referências } \\
\text { ("Eu não escolheria um usuário sem referências") }\end{array}$ & $40,6 \%$ & $30,2 \%$ & $29,2 \%$ \\
\hline Perfil Verificado & & & \\
\hline ("Eu não possuo mas confio mais em um perfil verificado") & $50 \%$ & $26,4 \%$ & $23,6 \%$ \\
\hline ("Eu possuo e confio mais em um perfil verificado") & $66,7 \%$ & $18,3 \%$ & $15 \%$ \\
\hline $\begin{array}{l}\text { Redes Sociais (Facebook) } \\
\text { ("Eu confio mais em usuários com redes sociais vinculadas") }\end{array}$ & $52 \%$ & $25,4 \%$ & $22,6 \%$ \\
\hline $\begin{array}{l}\text { Informação Declarada e Fotos Pessoais } \\
\text { ("Quanto mais fotos e informações pessoais, mais eu confio em } \\
\text { um usuário") }\end{array}$ & $54,7 \%$ & $26,4 \%$ & $18,8 \%$ \\
\hline $\begin{array}{l}\text { Rede Social da plataforma } \\
\text { ("Confio mais no usuário que possui muitos amigos na rede") }\end{array}$ & $28,4 \%$ & $35,8 \%$ & $35,8 \%$ \\
\hline
\end{tabular}


Chat Interno da plataforma

("Eu realizo toda a comunicação no chat interno da plataforma") 35,5\% - $\quad$ - $\quad 64,2 \%$

("Eu me sinto mais seguro através da comunicação pelo chat") $\quad 26,4 \% \quad 31,1 \% \quad 42,5 \%$

Equipe de Suporte

$15,1 \%$

$84,9 \%$

("Eu já solicitei a equipe especializada de suporte")

Fonte: autores

Por fim, foram listados os principais mecanismos de confiança presentes no Couchsurfing, e questionado aos usuários qual era o mecanismo de maior importância para a tomada de decisão. Os resultados estão representados no Gráfico 1 abaixo.

Gráfico 1 - Percepção dos entrevistados quanto aos mecanismos de confiança

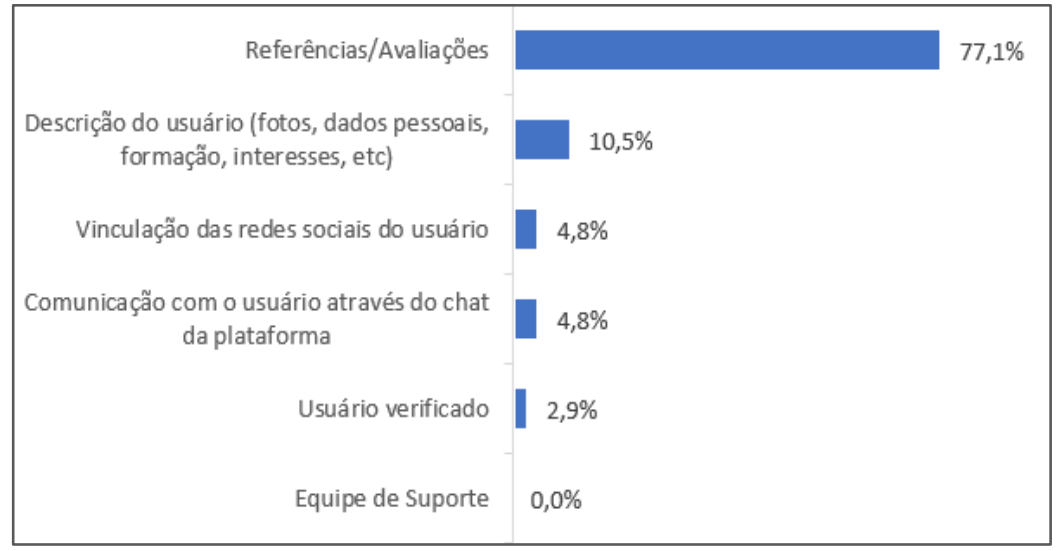

Fonte: autores

\section{Discussão}

No Gráfico 1 constata-se que a grande maioria dos usuários afirmou que as referências são o mecanismo de confiança mais relevante da plataforma. Dessa forma, conclui-se que a análise das referências de um usuário é imprescindível no processo de tomada de decisão, definindo a reputação do usuário em meio a comunidade. Ou seja, quanto mais referências positivas um usuário tiver, maior a garantia do mesmo ser um indivíduo confiável e de não representar riscos e ameaças.

Ainda em relação às avaliações, foi perguntado aos membros da plataforma se eles negariam hospedar ou ser hospedado por um usuário que nunca realizou uma experiência no Couchsurfing. Como pode ser observado no Quadro 2, não houve um consenso entre os usuários sobre essa afirmação. Isso corrobora que, por mais que a referência seja o dado mais importante na opinião dos entrevistados, todo novo usuário ingressa na plataforma sem avaliações. Portanto, por mais que seja mais difícil confiar em um usuário sem nenhum tipo de referência dada por membros da comunidade, muitos usuários estão abertos a serem a sua primeira experiência.

Constatou-se também que 60 usuários possuíam um perfil verificado, contudo, não houve um consenso sobre a relevância da sua importância entre os usuários. Entre os usuários entrevistados, a opinião divergiu bastante quanto à importância da verificação para a confiança: 
"Na experiência boa que tive, o usuário não era verificado. Já na experiência ruim, a usuária era verificada. Portanto, aumenta muito pouco minha confiança" (Ator 2, 21 anos, estudante universitário).

Contudo, quando se analisa a afirmação entre os usuários que possuem o perfil verificado, percebe-se uma maior relevância nessa funcionalidade da plataforma, no qual a grande maioria afirmou que concorda com a afirmação.

Além disso, a maioria dos usuários afirmou que sente uma maior confiança em um usuário que vincula redes sociais no perfil. Esse resultado corrobora a hipótese de que a vinculação de redes sociais traz uma maior credibilidade ao perfil, já que nas redes sociais estão visíveis as interações do usuário com seus amigos, suas opiniões, interesses pessoais, e demais informações pertinentes, ajudando a tirar o usuário do anonimato.

E o mesmo vale para as fotos e informações pessoais declaradas pelo usuário. A plataforma permite que usuários possam adicionar centenas de fotos, que auxiliam na formação da imagem do usuário, e detalhar sua formação, sua ocupação e seus principais gostos e experiências vividas, e a maioria dos usuários participantes concordou que o nível de confiança aumenta com a quantidade de informações declaradas.

Em relação aos amigos adicionados na própria rede social da plataforma, apenas $27,6 \%$ dos usuários concordaram que a confiança aumenta em um usuário que possui muitos amigos adicionados. Esses dados revelam que esse mecanismo não possui relevância para a tomada de decisão do usuário, ao decidir se o perfil é confiável ou não. $\mathrm{O}$ ato de adicionar um usuário à sua rede de amigos é uma tarefa trivial, e não supõe que os usuários já tenham tido alguma experiência ou interagido entre si.

A grande maioria dos participantes revelou que não utilizam o chat da plataforma, e apenas $24,5 \%$ concordam com a afirmação de que se sentem mais seguros quando toda a comunicação é realizada através do chat da plataforma. Muitos usuários relataram preferências por outros recursos, como a opinião abaixo:

"Normalmente inicio a conversa pelo chat e sigo para o Whatsapp por ser mais dinâmico" (Ator 3, 33 anos, escritor e turismólogo).

Já em relação ao suporte realizado pela equipe especializada do Couchsurfing, a grande maioria dos participantes afirmou nunca terem utilizado o serviço. Dos 16 participantes que utilizaram o serviço, 62,5\% o consideram "Excelente" ou "Bom", enquanto 37,5\% o consideram "Ruim" ou "Péssimo". Dos entrevistados, apenas um precisou contatar a equipe de suporte da plataforma. De acordo com o seu relato, sofreu um abuso por parte do anfitrião da casa:

"Um homem de Londres me hospedou e, enquanto eu dormia obviamente alcoolizado, me acordou enquanto praticava sexo oral em mim" (Ator 4, 27 anos, estudante de medicina).

De acordo com o entrevistado, a equipe agiu corretamente, apesar de ter agido de forma lenta:

"Foram eficientes em expulsar o abusador da comunidade, mesmo que tenha demorado algum tempo para isso (cerca de 2 semanas)". 


\section{Conclusão}

A plataforma Couchsurfing é um dos principais símbolos da economia colaborativa, por ser uma plataforma de acomodação gratuita que oferece uma forma alternativa e autêntica de turismo, permitindo que viajantes ao redor de todo o mundo possam se conectar entre si, hospedando ou sendo hospedados e compartilhando diferentes culturas e experiências juntos.

Os dados obtidos pelos questionários e entrevistas, apesar de serem uma amostra relativamente pequena do Couchsurfing, foram bastante significativos, contemplando usuários de diferentes gêneros, idades e tipos de experiências realizadas na plataforma, agregando mais valor às respostas obtidas na pesquisa.

Os resultados confirmam que as referências são o principal mecanismo de confiança no Couchsurfing, e provavelmente nas demais plataformas colaborativas existentes. Trata-se da funcionalidade que define a reputação do usuário perante a comunidade, ou seja, como foram suas experiências passadas, identificando a opinião de usuários sobre o que acharam e comentaram dessas experiências.

Dessa maneira, o Couchsurfing e demais plataformas colaborativas precisam ficar atentas a importância desse mecanismo, dedicando um espaço exclusivo e em destaque para as referências e estimulando a realização de avaliações sinceras entre usuários após o fim experiência.

Além disso, plataformas colaborativas, como o Couchsurfing e BlaBlaCar, devem estimular que seus membros se expressem em seus perfis, um fator que facilita a construção da confiança perante a comunidade. Nessa questão, o Couchsurfing realiza um ótimo papel, fornecendo perguntas a serem respondidas pelos usuários, como seus principais interesses, coisas incríveis que já fez e o porquê se cadastrou na plataforma.

As plataformas devem investir também em chats mais dinâmicos e de interface mais convidativa, já que afirmam que a resolução de eventuais problemas é mais ágil quando toda a comunicação ocorre internamente. Esse investimento é capaz de aumentar a parcela de usuários que se comunicam através do chat, aumentando assim o controle dessas plataformas no serviço oferecido.

Em relação ao suporte, as plataformas devem ter como prioridade formar uma equipe de pronto atendimento para resolver questões relativas à segurança. Por mais que a grande maioria das referências dos usuários do Couchsurfing sejam positivas, são necessários recursos mais dinâmicos, como uma equipe de telefonia disponível 24 horas por dia, ou um chat direto com a equipe de suporte para reportar problemas e emergências. O contato com a plataforma através de e-mail e preenchimento de um formulário é suficiente apenas para sanar dúvidas e resolver problemas menos urgentes, mas extremamente lento e ineficaz para situações de risco e emergências.

Como visto anteriormente, um dos usuários entrevistados relatou um abuso sexual ocorrido durante uma experiência na plataforma, e foi criticada justamente a lentidão da equipe de suporte em expulsar o abusador da comunidade. Questões críticas como abusos sexuais e violências físicas em experiências no Couchsurfing, e em demais plataformas colaborativas, encorajam o debate sobre como as plataformas devem se posicionar frente aos riscos intrínsecos a esses serviços. 
É necessário que essas plataformas se pronunciem quanto a essas questões, elaborem soluções inteligentes e forneçam uma resposta rápida aos usuários. Indivíduos que cometem crimes devem ser expulsos da comunidade, além de responderem na justiça por suas ações. Portanto, deveria ser de responsabilidade das plataformas facilitarem o processo de denúncia e exclusão do indivíduo da comunidade, impedindo que o mesmo possa reingressar com um perfil diferente.

A análise de como é projetada a confiança em plataformas colaborativas, e como a mesma é percebida pelos usuários dessas plataformas, é de grande importância para a gestão dessas plataformas. As respostas obtidas através dos questionários e entrevistas podem ajudar os gestores de plataformas colaborativas a lidar estrategicamente com a gestão da confiança nas plataformas, implementando novas estratégias de marketing direcionadas a seu público alvo e atraindo novos membros.

Os resultados desse estudo servem como um direcionamento para plataformas colaborativas já existentes reavaliarem e adequarem a forma como projetam a confiança para o usuário, seja através de mecanismos de confiança ou através do marketing e comunicação com o cliente. Além disso, os resultados servem como um direcionamento para novos e futuros empreendimentos no setor, que procuram priorizar a segurança do usuário e promover uma maior confiança no serviço prestado.

Contudo, esse estudo não é livre de limitações. A pesquisa realizada com usuários da plataforma Couchsurfing abordou somente habitantes da cidade do Rio de Janeiro, e os resultados da percepção de confiança na plataforma não são universais, podendo ser inválidos em diferentes países, principalmente aqueles que possuem uma cultura muito diferente da do Brasil.

Como sugestões de pesquisas futuras, a realização de uma pesquisa de percepção de confiança na plataforma Couchsurfing somente destinada a usuárias do gênero feminino seria interessante, pois trata-se de um perfil mais preocupado com questões de segurança e mais suscetível a riscos.

\section{Referências Bibliográficas}

BOTSMAN, R.; ROGERS, R. What's Mine is Yours: The Rise of Collaborative Consumption. New York: Harper Collins. 2010

BROWN, L. The Transformative Power Of The International Sojourn. An Ethnographic Study of the International Student Experience. Annals of Tourism Research, v. 36, n. 3, p. 502-521, 2009.

DECROP, A.; CHIAPPA, G.; MALLARGÉ, J.; ZIDDA, P. Couchsurfing has made me a better person and the world a better place: the transformative power of collaborative tourism experiences. Journal of Travel and Tourism Marketing, v. 35, n. 1, p. 57-72, 2018.

ERTZ, M.; DURIF, F.; ARCAND, M. Collaborative Consumption: Conceptual Snapshot At a Buzzword. Journal of Entrepreneurship Education, Vol. 19 No. 2, pp. 1-23, 2016.

FANG, Y; QURESHI I; SUN, H; MCCOLE, P; RAMSEY, E, LIM, K. Trust, satisfaction, and online re-purchase intention: The moderating role of perceived effectiveness of ecommerce institutional mechanisms. MIS Quart. v. 38, n. 2, p. 407-427, 2014. 
GUTTENTAG, D. Airbnb: disruptive innovation and the rise of an informal tourism accommodation sector. Current Issues in Tourism, v. 18, n. 12, p. 1192-1217, 2015.

HOWALDT, J.; KOPP, R.; SCHWARZ, M. Social innovations as drivers of social change. Tarde's disregarded contribution to social innovation theory building. Social Frontiers. The next edge of social innovation research, p. 29-51, 2013.

LEADBEATER, C. We-Think: Mass Inovation not Mass production. Profile Books, 2008.

MAYER, R. C.; DAVIS, J. H.; SCHOORMAN, F. D. An integrative model of organizational trust. Academy of Management Review, v. 20, n.3, p. 709-734, 1995.

MÖHLMANN, M. Collaborative consumption: determinants of satisfaction and the likelihood of using a sharing economy option again. Journal of Consumer Behaviour, v. 14, p. 193-207, 2015.

MÖHLMANN, M. Digital Trust and Peer-to-Peer Collaborative Consumption Platforms: A Mediation Analysis. Ssrn, p. 1-38, 2016.

MÖHLMANN, M.; GEISSINGER, A. Trust in the Sharing Economy: Platform-Mediated Peer Trust. Cambridge Handbook of the Law and Regulation of the Sharing Economy, v. 70, n. 1, p. 26-44, 2018.

MOLZ, J. G.; GIBSON, S;. Mobilizing Hospitality: The Ethics of Social Relations in a Mobile World. Aldershot: Ashgate. 2012

MOSEDALE, J.; VOLL, F. Social innovation in Tourism: Social Practices Contributing to Social Development. Social Entrepreneurship and Tourism, Springer International Publishing, pp. 101-115, 2017.

MOULAERT, F.; MARTINELLI, F; SWYNGEDOUW, E.; GONZALEZ, S. Towards alternative model(s) of local innovation. Urban Studies, v. 42, n. 11, p. 1969-1990, 2005.

PWC. Consumer intelligence series: the Sharing Economy, 2015. Disponível em: $<$ www.pwc.com/us/en/technology/publications/assets/pwc-consumer-intelligenceseries-the-sharing-economy.pdf>. Acesso em: 15 de Mar. de 2019

STEYLAERTS, V.; DUBHGHAILL, S. O. CouchSurfing and authenticity: Notes towards an understanding of an emerging phenomenon. Hospitality \& Society, v. 1, n. 3, p. 261278, 2012.

TANZ, J. How Airbnb and Lyft Finally Got Americans to Trust Each Other, 2014. Disponivel em: < https://www.wired.com/2014/04/trust-in-the-share-economy/>. Acesso em: 06 de Maio de 2019.

TRENZ, M.; FREY, A.; VEIT, D. Disentangling the facets of sharing. Internet Research, v. 28, n. 4, p. 888-925, 2018. 